Proceeding Paper

\title{
Bioactivity of Essential Oils and Respective Volatile Monoterpenoids against Thaumetopoea pityocampa and T. wilkinsoni ${ }^{\dagger}$
}

\author{
Jorge M. S. Faria ${ }^{1,2}$ (D)
}

check for

updates

Citation: Faria, J.M.S. Bioactivity of Essential Oils and Respective Volatile Monoterpenoids against

Thaumetopoea pityocampa and T. wilkinsoni . Biol. Life Sci. Forum 2021,

3, 36. https://doi.org/10.3390/

IECAG2021-09692

Academic Editor: Cornelia Rumpel

Published: 1 May 2021

Publisher's Note: MDPI stays neutral with regard to jurisdictional claims in published maps and institutional affiliations.

Copyright: (C) 2021 by the author. Licensee MDPI, Basel, Switzerland. This article is an open access article distributed under the terms and conditions of the Creative Commons Attribution (CC BY) license (https:// creativecommons.org/licenses/by/ $4.0 /)$.
1 INIAV, I.P., National Institute for Agrarian and Veterinarian Research, Quinta do Marquês, 2780-159 Oeiras, Portugal; fariajms@gmail.com

2 MED, Mediterranean Institute for Agriculture, Environment and Development, Institute for Advanced Studies and Research, Évora University, Pólo da Mitra, Ap. 94, 7006-554 Evora, Portugal

+ Presented at the 1st International Electronic Conference on Agronomy, 3-17 May 2021; Available online: https:/ / sciforum.net/conference/IECAG2021.

\begin{abstract}
The pine processionary moth (PPM) is a dangerous parasitic insect pest of several pine species in the Mediterranean basin, causing defoliation and promoting tree decline. Larvae release urticating hairs that cause strong allergic reactions in humans and animals. Pest management practices implemented by national health authorities include the eradication of nests and application of chemical insecticides. However, commercial pesticides can induce PPM resistance and be harmful to the environment and human health. Essential oils (EOs) are environmentally friendlier alternatives to commercial insecticides. The present review analyses the existing body of work on the biological activity against the PPM and highlights the most successful EOs. A total of nine publications were identified, reporting on the biological activity of 38 EOs extracted from 31 plant species against the PPM. The EOs extracted from Achillea arabica, Citrus aurantium, Lavandula angustifolia, Origanum onites and Thymus vulgaris showed the lowest half maximal lethal concentrations $\left(\mathrm{LC}_{50}\right)$. O. onites EO components with the highest activities were the monoterpenoid isomers carvacrol and thymol. The use of EOs is a potential ecofriendly alternative for successful PPM pest management, however more extensive studies must be performed to pinpoint highly active and easily accessible EOs and respective volatiles.
\end{abstract}

Keywords: essential oils; forest health; green pesticides; insecticides; pine processionary moth; Pinus; sustainable pest management; Thaumetopoea

\section{Introduction}

The environmental alterations that result from climate change and the increase in trading activities have been strong promoters of epidemic events in Mediterranean conifer forests, such as the pinewood nematode or the pine processionary moth (PPM). Thaumetopoea species (Lepidoptera: Thaumetopoeidae) that feed on pine needles in the winter are commonly called PPM. While T. pityocampa Den. \& Schiff. can be found in Europe and North Africa, T. wilkinsoni Tams. is common in Asia and the Middle East [1]. The larval stages of the PPM cause pine defoliation and enable attacks from other opportunistic pine pests, which leads to a strong decline in pine vitality and yield of edible pine nuts. The PPM life cycle has two phases, an aerial phase comprising the egg, larvae and adult, and an underground phase, the pupa. The moth emerges from underground in the summer, reproduces and oviposits in the branch tips of the upper crown of pine trees. As eggs hatch, the larvae begin feeding on pine needles and moult. By the fourth instar, the recognizable silken nests that characterize this pest have enlarged to the definitive winter nest. Fully grown larvae (fifth instar) emerge in the beginning of spring and seek out pupation sites in the soil, in long head-to-tail processions [2]. In addition to the heavy impacts on 
biodiversity and the environment, the PPM has a dangerous societal impact due to its urticating hairs produced from the third instar onwards, that cause strong allergic reactions. The allergenic protein thaumetopoein is responsible for causing conjunctivitis, respiratory congestions and asthma, both in humans and animals [3]. Several pest-management tactics are employed to control PPM populations. Besides the phytosanitary measures applied to pine nurseries, PPM is controlled by mechanical means, through cutting and burning winter nests, by biological means, such as natural enemies and predators and the application of microbial insecticides based on Bacillus thuringiensis, or by chemical means employing aerial spraying of commercial insecticides [4]. However, severe adverse effects can be associated with many insecticides, particularly in the elimination of nontarget or beneficial species, and environmental and human health issues. The use of plant natural compounds has shown promise, being the source of many highly active phytochemicals. In this respect, essential oils (EOs) can be regarded as potential sustainable chemical control agents [5]. EOs are mostly composed of terpenoids (mainly mono- and sesqui-terpenes) and phenolic compounds, such as phenylpropanoids, that can often display additive, synergistic and antagonistic interactions associated with their biological activities. Additionally, these mixtures have the advantage of not accumulating in the environment and having a broad range of activities, which diminishes the risk of developing resistant pathogenic strains [6]. The present review analyses the existing body of work on the biological activity of EOs against the PPM and highlights the most successful plant families and EOs.

\section{Reports on Insecticidal EOs against the Pine Processionary Moth}

Research on reported work was performed on the Web of Science search engine, in all available databases, using the topics "Thaumetopoea" and "essential oil". Information on the family and species of the plant source and technique used for EO extraction, EO solubilizer, PPM species and life stage used in bioassays as well as EO activity (half maximal effective concentration $\left(\mathrm{EC}_{50}\right)$ or mortality), was collected when available.

Nine publications were identified that reported on the activity of EOs on the PPM [1,3-5,7-11]. The reports were published in journals mainly dedicated to the scientific areas of entomology (44\%), agronomy (33\%), multidisciplinary agriculture (22\%) and forestry (22\%). The identified publications were cited by over 80 works (77, if publications in the present list are excluded) in a total of 102 citations (89, if citations from works in the present list are excluded), with an average of 11.3 citations per item. The citing publications were mostly from the areas of plant sciences, agriculture, chemistry, environmental sciences, and ecology. The first report was published in 2004 and the last in 2020 (the year with the most publications) (Figure 1a). Citations increased until 2008 and showed a stable average number until 2018, but have since exponentially increased (Figure 1a). Recent scientific interest appears to be rising.

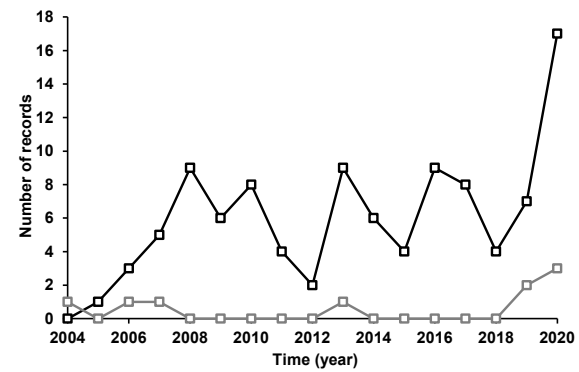

(a)

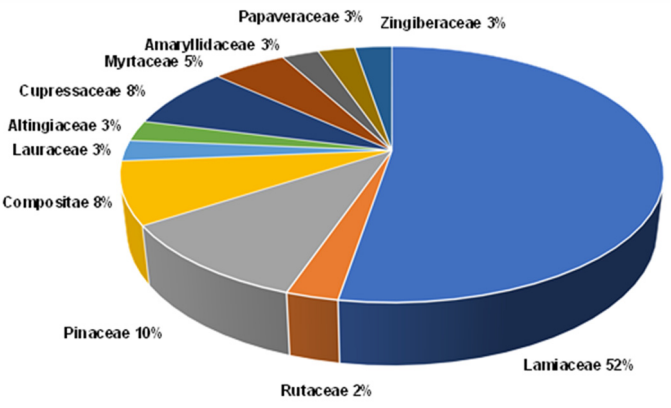

(b)

Figure 1. Yearly number of publications on the activity of essential oils against the pine processionary moth ( $\square$ ) and yearly number of citations on these publications (ם) (a). Percentage of essential oils tested against the pine processionary, distributed by family of plant source (b). 


\section{Active Essential Oils (EOs)}

The 38 EOs tested against the PPM were extracted from various parts of the shoots of 31 plant species. Over $50 \%$ of the source plants belong to the Lamiaceae family, while the remaining belong to Altingiaceae, Amaryllidaceae, Compositae, Cupressaceae, Lauraceae, Myrtaceae, Papaveraceae, Pinaceae, Rutaceae and Zingiberaceae (Figure 1b). The most active EOs were extracted mainly from plants of the Lamiaceae family. Concerning their extraction, the tested EOs were either obtained by steam-distillation (24\%) or hydrodistillation (18\%). In $58 \%$ of the EOs, information on the extraction method is either not available or EOs were acquired from commercial sources and the extraction method is not mentioned (Figure 2a). Concerning the bioassays, the EOs were used in aqueous solutions in their pure form $(16 \%)$, in $0.3 \%$ of the nonionic surfactant Tween $80(32 \%)$ or dissolved in the organic solvent ethanol (16\%). In $21 \%$ of EOs, information on the solubilizer compound is not available. Bioassays were mainly performed on the moth larvae or on the silken nests, and mortality was evaluated in all larval stages, with special incidence in 3rd, 4th, and 5th instars. Over $70 \%$ of bioassays were performed in T. pityocampa and $26 \%$ in T. wilkinsoni (Figure 2b).

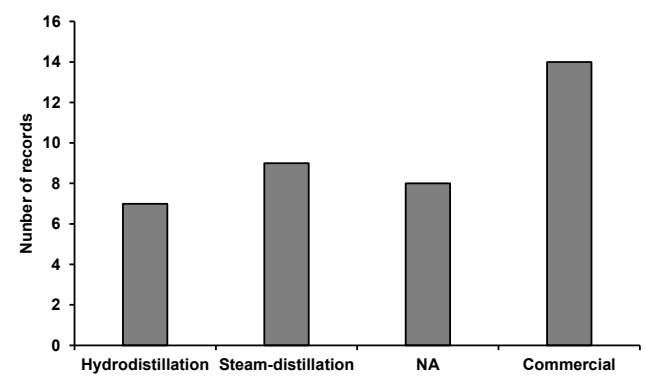

(a)

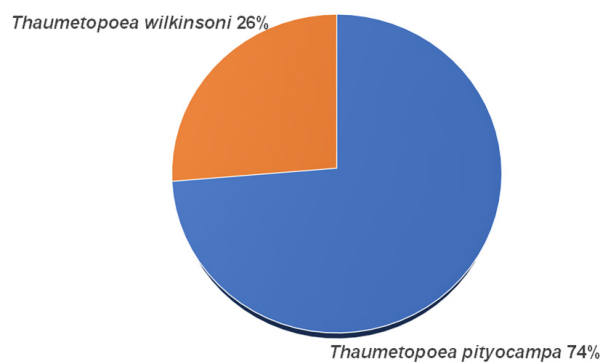

(b)

Figure 2. Number of EOs obtained from commercial sources, by steam-distillation or hydrodistillation (a) and percentage of bioassays performed on Thaumetopoea pityocampa or T. wilkinsoni pine processionary moth species (b). NA corresponds to reported EOs where information on extraction methods was not available.

The lowest $\mathrm{LC}_{50}$ values were reported for the EOs extracted from Achillea arabica (0.12 to $2.53 \mu \mathrm{L} /$ Larva), Citrus aurantium $(5.33 \mu \mathrm{L} / \mathrm{mL})$, Lavandula angustifolia $(0.92 \mu \mathrm{L} / \mathrm{mL})$, Origanum onites ( 2.9 to $3.8 \mu \mathrm{L} / \mathrm{mL}$ ) and Thymus vulgaris $(0.22 \mu \mathrm{L} / \mathrm{mL})[1,4,7,11]$. A higher $\mathrm{LC}_{50}$ was reported for Pinus brutia EO, namely $188 \mu \mathrm{L} / \mathrm{mL}$ [9]. Complete mortalities (100\%) were detailed for EOs extracted from A. gypsicola, O. acutidens, O. onites, O. rotundifolium, Satureja hortensis, S. spicigera and Tanacetum polycephalum. Additionally, mortalities above 90\% were reported for the EOs of Salvia officinalis (95\%), Papaver somniferum (95\%) and Allium sativum (90\%) $[3,8,10]$. Concerning the time needed to reach complete mortality, the EOs extracted from Laurus nobilis, Pinus brutia and T. vulgaris showed the fastest activities, reaching complete PPM mortality between 0.75 and 0.79 min at $25 \%$ concentrations [5].

\section{Active Volatiles from EOs}

In five publications, the composition of active EOs was reported. The main EO compounds were identified for Achillea arabica, Laurus nobilis, Origanum onites, Pinus brutia and Thymus vulgaris (Table 1). EOs were rich in monoterpenoids and sesquiterpenes.

Cetin et al. [1] identified carvacrol, thymol, $\gamma$-terpinene and terpinen-4-ol as the main components of $O$. onites $\mathrm{EO}$, and tested each pure $\mathrm{EO}$ compound, acquired from commercial sources, against the PPM. Carvacrol (Figure 3a) and thymol (Figure 3b). showed the highest activities, reaching $\mathrm{LC}_{50}$ values of 3.1 and $5.5 \mu \mathrm{L} / \mathrm{mL}$, respectively, while the original EO showed an $\mathrm{LC}_{50}$ value of $3.8 \mu \mathrm{L} / \mathrm{mL}$. Differential $\mathrm{LC}_{50}$ values may indicate an isomeric specificity in activity against PPM that can be explored for the establishment of directed pest-management practices. 
Table 1. Reported main composition of essential oils ( $\geq 5 \%$, when mentioned) with activity against the pine processionary moth.

\begin{tabular}{ccc}
\hline Species & Ref. & Main Compounds $(\geq \mathbf{5 \%}$, When Mentioned $)$ \\
\hline Achillea arabica & {$[4]$} & $\gamma$-terpinene 38, camphor 24, borneol $6, \alpha$-terpineol 5 \\
Laurus nobilis & {$[5]$} & cineole, geraniol, eugenol, several monoterpenes \\
Origanum onites & {$[1]$} & carvacrol, thymol, $\gamma$-terpinene, terpinen- 4 -ol \\
Pinus brutia & {$[5]$} & $\alpha$-pinene, $\beta$-pinene, camphene, $\delta$-3-carene, limonene, $\beta$-myrcene \\
Pinus brutia & {$[9]$} & $\beta$-pinene $38, \alpha$-pinene 25, trans- $\beta$-caryophyllene 15 \\
Thymus vulgaris & {$[5]$} & carvacrol, $p$-cymene, thymol \\
Thymus vulgaris & {$[11]$} & carvacrol $71, p$-cymene $8, \gamma$-terpinene 6 \\
\hline
\end{tabular}

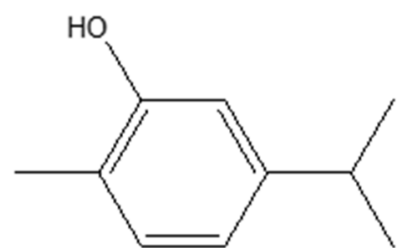

carvacrol

(a)

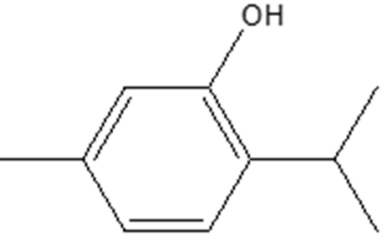

thymol

(b)

Figure 3. Chemical structure of carvacrol (a) and thymol (b), the main compounds of O. onites EO.

\section{Conclusions}

The use of EOs can be a valuable tactic for the establishment of sustainable pestmanagement strategies in the control of the pine processionary moth. In comparison with other pine pests, the screening of EOs against the PPM is still in its early stages. Only a small number of EOs were tested and not all were chemically characterized. A greater number of EOs must be assayed and characterized to provide a clearer view of the main families and plant species with highly active phytochemicals and ascertain the most active EO components. The reports reviewed in the present work point towards the Lamiaceae family as an important source of plant species with highly active EOs against the PPM. This family should be further screened for active EOs and their composition fully detailed to allow linking the chemical properties of EO compounds to their specific activity. For example, O. onites EO was highly active against the PPM and was found to be composed of compound isomers (carvacrol and thymol) that display different activities. Other plants with EOs with higher proportions of these compounds should be screened, and the functional diversity displayed by the isomers must be assessed for other compounds. This information can contribute to the identification of specific mechanisms of action in the PPM, which can be explored in greener, precision pest-management tactics.

Funding: This research received no external funding.

Institutional Review Board Statement: Not applicable.

Informed Consent Statement: Not applicable.

Data Availability Statement: The raw data supporting the findings of this study are available from the corresponding author (Jorge M. S. Faria) upon reasonable request.

Conflicts of Interest: The authors declare no conflict of interest.

\section{References}

1. Cetin, H.; Erler, F.; Yanikoglu, A. A comparative evaluation of Origanum onites essential oil and its four major components as larvicides against the pine processionary moth, Thaumetopoea wilkinsoni Tams. Pest Manag. Sci. 2007, 63, 830-833. [CrossRef] [PubMed]

2. Masutti, L.; Battisti, A. Thaumetopoea pityocampa (Den. \& Schiff.) in Italy Bionomics and perspectives of integrated control. J. Appl. Entomol. 1990, 110, 229-234. [CrossRef] 
3. Güven, Ö.; Aydin, T.; Karaca, I.; Butt, T. Biopesticides offer an environmentally friendly solution for control of pine processionary moth (Thaumetopoea wilkinsoni Tams) larvae and pupae in urban areas. Biocontrol Sci. Technol. 2020, 31, 35-52. [CrossRef]

4. Kesdek, M.; Kordali, Ş.; Usanmaz Bozhüyük, A.; Güdek, M. Larvicidal effect of Achillea biebersteinii Afan. (Asteraceae) essential oil against larvae of pine processionary moth, Thaumetopoea pityocampa (Denis \& Schiffermüller, 1775) (Lepidoptera: Notodontidae). Turk. J. Agric. For. 2020, 44, 451-460. [CrossRef]

5. Kanat, M.; Alma, M.H. Insecticidal effects of essential oils from various plants against larvae of pine processionary moth (Thaumetopoea pityocampa Schiff) (Lepidoptera: Thaumetopoeidae). Pest Manag. Sci. 2004, 60, 173-177. [CrossRef] [PubMed]

6. Figueiredo, A.C.; Barroso, J.G.; Pedro, L.G.; Scheffer, J.J.C. Factors affecting secondary metabolite production in plants: Volatile components and essential oils. Flavour Fragr. J. 2008, 23, 213-226. [CrossRef]

7. Cetin, H.; Erler, F.; Yanikoglu, A. Toxicity of essential oils extracted from Origanum onites L. and Citrus aurentium L. against the pine processionary moth, Thaumetopoea wilkinsoni Tams. Folia Biol. 2006, 54, 153-157. [CrossRef] [PubMed]

8. Kesdek, M.; Bayrak, N.; Kordali, S.; Usanmaz, A.; Contuk, G.; Ercisli, S. Larvicidal effects of some essential oils against larvae of the Pine processionary moth, Thaumetopoea pityocampa (Denis \& Schiffermüller) (Lepidoptera: Thaumetopoeidae). Egypt. J. Biol. Pest Control 2013, 23, 201-207.

9. Semiz, G.; Kocabıyık, K.; Cetin, H. Larvicidal effect of Pinus brutia Ten. seed essential oil to pine processionary moth (Thaumetopoea wilkinsoni Tams.) under laboratory conditions. Fresenius Environ. Bullettin 2019, 28, 2375-2379.

10. Yiğit, Ş.; Saruhan, I.; Akça, I. The effect of some commercial plant oils on the pine processionary moth Thaumetopoea pityocampa (Lepidoptera: Notodontidae). J. For. Sci. 2019, 65, 309-312. [CrossRef]

11. Zahed, K.; Souttou, K.; Hamza, F.; Zamoum, M. Chemical composition and larvicidal activities in vitro and in vivo of essential oils of Thymus vulgaris (L.) and Lavandula angustifolia (Mill) against pine processionary moth Thaumetopoea pityocampa Den. \& Schiff. in Ain Defla (Algeria). J. Plant Dis. Prot. 2020, 128, 121-137. [CrossRef] 